\title{
Myocardial tagging in the polar coordinate system; early clinical experience
}

\author{
Sarah N Khan ${ }^{1 *}$, Abbas N Moghaddam², Razieh Kaveh², Adam Plotnik¹, Evan Lehrman', Ali Nsair ${ }^{1}$, J Paul Finn ${ }^{1}$ \\ From 17th Annual SCMR Scientific Sessions \\ New Orleans, LA, USA. 16-19 January 2014
}

\section{Background}

Quantitative MR myocardial strain analysis is typically performed using rectilinear or Cartesian grid tagging, and regional contractility is visually assessed by the deformation of the grid1. However, it is difficult to visually isolate circumferential and radial components of displacement and strain from parallel straight lines on short axis images. This study evaluates the potential of a polar coordinate tagging system 2 for quantification of circumferential myocardial displacement in a variety of clinical conditions.

\section{Methods}

33 subjects including 12 patients with congenital heart disease (CHD), 11 with cardiomyopathy (CM) and 10 healthy volunteers (HV) underwent cardiac SSFP cine and myocardial tagging in the mid-ventricular short axis plane with grid tags (line separation 5-7 mm), circular tags ( $5 \mathrm{~mm}$ separation) and radial tags (11 lines per semi-circle; 18 degree separation). Visual assessment of circumferential and radial displacement was performed by two observers for each of the six mid short axis segments. Scores were assigned for: overall tag quality (4 point scale), strain ( 5 point scale; normal +2 , hypokinesia 1 , akinesia 0 , mild dyskinesia -1 , severe dyskinesia $-2)$, confidence in the findings (3 point scale) and ease of interpretation (4 point scale). Quantitative analysis of global and segmental circumferential strain was performed using a semi-automated tool previously described3.

\section{Results}

Healthy volunteers (Figure 1) had the highest global circumferential strain $(-0.0836 \pm 0.0111)$, followed by CHD $(-0.0781 \pm 0.0157)$ and CM $(-0.0620 \pm 0.0192)$. Regional circumferential strain was highest in the inferolateral segment in all three groups (HV $-0.105 \pm 0.0342$, CM $-0.118 \pm 0.0306$, CHD $-0.139 \pm 0.0381)$. Regional circumferential strain was lowest in the anteroseptal segment in the CHD group $(0.0596 \pm 0.0316)$, anteroseptal and inferoseptal segments in the CM group (0.0429 \pm 0.0477 and $-0.0600 \pm 0.0482$ ), anteroseptal and anterior segments in the HV group $(-0.0571 \pm 0.0279$ and $-0.0608 \pm 0.0659)$. Healthy volunteers had the highest scores for tag quality, strain, confidence and ease of interpretation, followed by CHD and CM patients. Polar tagging was easier to interpret (average score 3.6) than grid tagging (average score 2.9).

\section{Conclusions}

Polar tagging has advantages for the visual and quantitative assessment of myocardial strain. Compared to rectilinear tagging, radial tags are easier to interpret for isolation of circumferential and radial components of myocardial motion. Overall tag quality, strain, confidence in assessment and ease of interpretation of the image were highest in healthy volunteers, second highest $\mathrm{CHD}$ patients and lowest in CM patients.

\section{Funding}

n/a.

${ }^{1}$ Radiology, UCLA, Los Angeles, California, USA

Full list of author information is available at the end of the article 


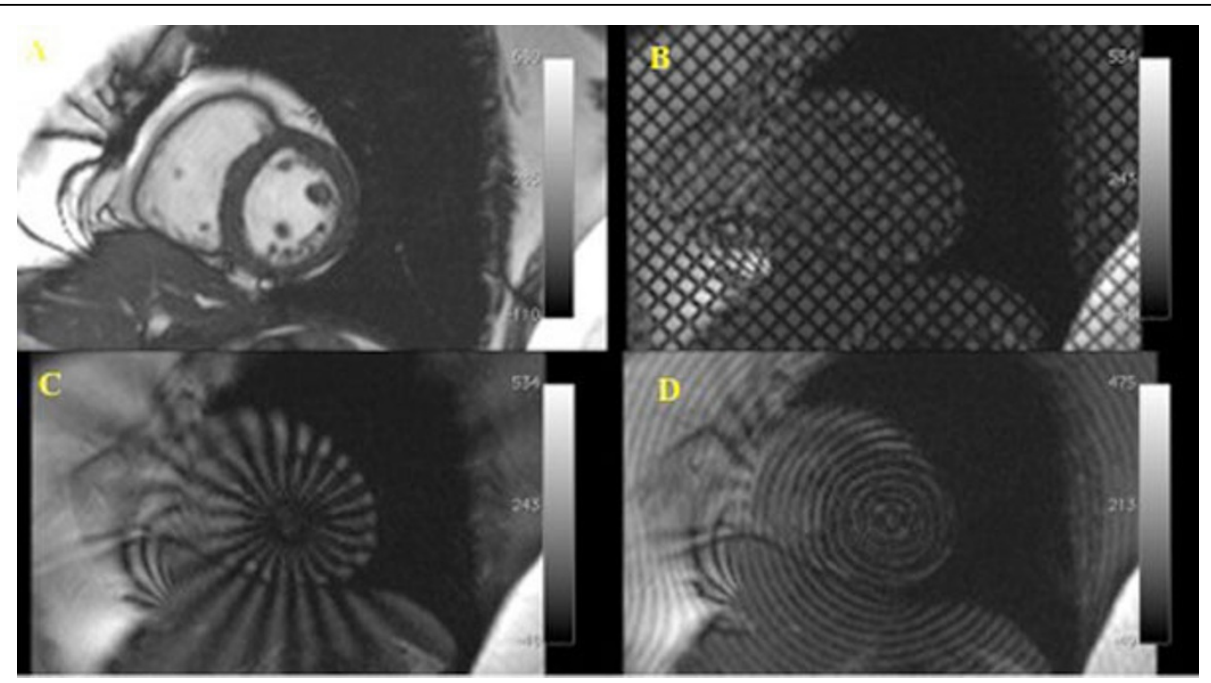

Figure 1 Images from a healthy volunteer. (A) SSFP Cine image in the mid ventricular slice (B) Cartesian grid tagging pattern (C) Radial tagging pattern (D) Circular tagging pattern.

\section{Authors' details}

'Radiology, UCLA, Los Angeles, California, USA. ²Biomedical Engineering,

Tehran Polytechnic, Tehran, Iran, Islamic Republic of.

Published: 16 January 2014

doi:10.1186/1532-429X-16-S1-P387

Cite this article as: Khan et al:: Myocardial tagging in the polar

coordinate system; early clinical experience. Journal of Cardiovascular

Magnetic Resonance 2014 16(Suppl 1):P387.

Submit your next manuscript to BioMed Central and take full advantage of:

- Convenient online submission

- Thorough peer review

- No space constraints or color figure charges

- Immediate publication on acceptance

- Inclusion in PubMed, CAS, Scopus and Google Scholar

- Research which is freely available for redistribution

Submit your manuscript at www.biomedcentral.com/submit
C Biomed Central 